\title{
ORNAMEN INDRAMAYU SEBAGAI RAGAM HIAS PADA BECAK JAKARTA
}

\author{
Sari Wulandari \\ Visual Communication Design, School of Design, BINUS University \\ Jln. K.H. Syahdan No. 9, Palmerah, Jakarta Barat 11480 \\ swulandari@binus.edu
}

\begin{abstract}
Indramayu ornaments that are painted on Jakarta's pedicabs have an exotic impression and a special attraction to the foreign tourists. The decorative ornament has the potential to be a valuable asset for the improvement of Indonesia art and design. The study was conducted with a qualitative research method of determining the location of culture through the stages of research, determination of informants, data collection and data analysis that were done by organizing, sorting, classifying and categorizing the data. Categorization is done based on the body parts of tricycles and obtained a variety of motives according to the space of placement the ornaments. By documenting and studying these ornaments, it can be improved due to nowaday needs, which would certainly enriches Indonesian decorative ornaments and utilized in broader needs.
\end{abstract}

Keywords: Ornaments, Indramayu, Pedicab, Jakarta

\begin{abstract}
ABSTRAK
Ornamen Indramayu yang dilukis pada badan becak Jakarta memiliki kesan eksotis dan berdaya tarik tersendiri bagi para turis mancanegara. Ornamen dekoratif ini berpotensi untuk menjadi aset yang berharga untuk perkembangan dunia desain dan seni di Indonesia. Penelitian dilakukan dengan metode penelitian kualitatif kebudayaan melalui tahapan penentuan lokasi penelitian, penentuan informan, pengumpulan data dan analisis data yang dilakukan dengan cara mengatur, mengurutkan, mengelompokkan dan mengkategorikan data. Pengkategorian dilakukan berdasarkan bagian-bagian pada badan becak dan diperoleh beragam motif sesuai bidang penempatan ornamen. Dengan mendokumentasikan dan memelajari ornamen ini maka dapat dilakukan pengembangan dari motif-motif ornamen untuk kebutuhan masa sekarang yang tentunya akan memperkaya khazanah ragam hias Indonesia dan dimanfaatkan untuk kebutuhan yang lebih luas.
\end{abstract}

Kata kunci: Ornamen, Indramayu, Becak, Jakarta 


\section{PENDAHULUAN}

Jakarta sebagai kota metropolitan dengan penduduknya yang heterogen dan strata ekonomi penduduknya yang beragam, memiliki berbagai moda transportasi yang melayani warganya dalam kebutuhan beraktivitas sehari-hari. Aneka moda transportasi tersedia di Jakarta, dari yang bersifat privat seperti taksi hingga massal seperti kereta api, dari yang merogoh kocek seharga puluhan ribu hingga yang cukup dibayar dengan beberapa lembar dua ribuan saja. Satu di antara moda transportasi yang pernah menjadi ikon kota Jakarta adalah becak. Becak (dari bahasa Hokkien: be chia yang artinya kereta kuda) adalah suatu moda transportasi beroda tiga yang umum ditemukan di Indonesia dan juga di sebagian Asia. Kapasitas normal becak adalah dua orang penumpang dan seorang pengemudi.

Becak pertama kali ditemukan di Jepang pada tahun 1869 dengan sebutan jinrikisha ("Jin" artinya "Orang", "riki" artinya "Tenaga", dan "sha" artinya "Kendaraan", yang kalau digabung artinya "Kendaraan Tenaga Manusia"). Pada tahun 1900-an jinrikisha dikenal oleh masyarakat Tiongkok dan dalam waktu singkat jinrikisha digunakan sebagai kendaraan pribadi kaum bangsawan dan kendaraan umum di Tiongkok. Kendaraan ini dalam bahasa Inggris diberi nama rickshaw, sementara penghelanya dinamakan hiki. Karena rickshaw adalah kendaraan roda dua dengan ban mati dan ditarik oleh manusia, mulai tahun 1970 para aktivis kemanusiaan melarang rickshaw beroperasi di seluruh jalan-jalan di negeri Tiongkok. Sebelum itu sekitar tahun 1950-an becak yang ditarik manusia ini sudah mulai menghilang dari Jepang.

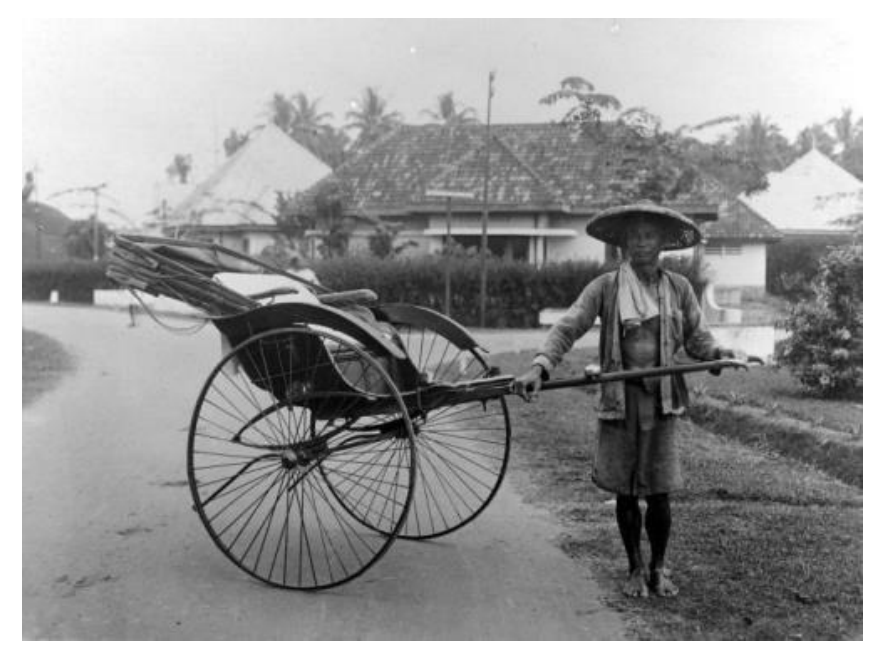

Gambar 1 Rickshaw (Sumber: Foto koleksi Tropenmuseum, Amsterdam, Belanda)

Becak di Jakarta diperkirakan masuk sekitar akhir tahun 1930-an. Lea Jellanik dalam Seperti Roda Berputar, menulis bahwa becak didatangkan ke Batavia dari Singapura dan Hongkong pada 1930-an. Jawa Shimbun terbitan 20 Januari 1943 menyebut bahwa becak diperkenalkan dari Makassar ke Batavia di akhir 1930-an. Data ini diperkuat dengan catatan perjalanan seorang wartawan Jepang ke berbagai daerah di Indonesia, termasuk Makassar. Dalam catatan berjudul Pen to Kamera terbitan 1937 itu disebutkan, becak ditemukan orang Jepang yang tinggal di Makassar, bernama Seiko-san.

Seiko-san memiliki toko sepeda yang saat itu mengalami sepinya penjualan, sehingga ia mencari cara agar tumpukan sepeda yang tak terjual bisa dikurangi. Kemudian ia membuat kendaraan roda tiga, dan terciptalah becak seperti yang umum dijumpai saat ini, memiliki tiga roda dengan ban angin dan dikayuh seperti sepeda. Pada tahun 1942 ketika Jepang datang ke Indonesia jumlah becak 
mengalami peningkatan yang begitu pesat. Hal ini disebabkan karena Jepang mengontrol dengan sangat ketat terhadap penggunaan bensin serta larangan kepemilikan kendaraan bermotor pribadi, sehingga becak merupakan alternatif terbaik moda transportasi di kota-kota besar seperti Jakarta dan Surabaya.

Becak merupakan alat angkutan yang ramah lingkungan karena tidak menyebabkan polusi udara (kecuali becak bermotor tentunya). Selain itu, becak tidak menyebabkan kebisingan dan juga dapat dijadikan sebagai objek wisata bagi turis-turis mancanegara. Keberadaan becak juga penting sebagai alat transportasi yang diandalkan oleh masyarakat menengah khususnya di perkampungan kota Jakarta, sehingga becak menjadi artefak budaya masyarakat Jakarta. Namun, sayangnya dengan jumlah becak yang begitu tinggi di Jakarta, kehadiran becak banyak mengganggu kelancaran lalu lintas karena kecepatannya yang lamban dibandingkan dengan mobil maupun sepeda motor.

Pada tahun 1988 Pemda mengeluarkan Perda No 11 tahun 1988 mengenai Ketertiban Umum bahwa keberadaan becak dilarang di Jakarta karena dianggap menjadi penyebab kemacetan di kota Jakarta, selain dianggap sebagai moda transportasi yang tidak manusiawi karena dioperasikan dengan tenaga manusia. Becak kemudian dibuang ke laut dan lambat laun jumlah becak berkurang. Puncaknya adalah pada tahun 1994 di mana becak sudah dilarang beroperasi di Jakarta. Sebagai penggantinya adalah helicak, bajaj dan kancil yang digerakkan dengan motor sehingga dapat melaju lebih cepat. Selain itu pengemudinya pun terlindung dari panas dan hujan sehingga terlihat lebih manusiawi.

Sesungguhnya keberadaan becak di Jakarta dapat dipertahankan untuk keperluan mendukung pariwisata kota Jakarta. Dengan bentuknya yang unik serta lukisan yang menghiasi badan becak menjadi daya tarik tersendiri karena penampilannya yang terlihat eksotis di mata para turis mancanegara. Becak yang difungsikan untuk mendukung pariwisata sudah dilakukan di Yogyakarta, Makassar di mana Pemda setempat memberikan pelatihan kepada para pengemudi becak agar dapat berkomunikasi dengan baik, bahkan dapat menjelaskan objek-objek pariwisata kepada turis. Meskipun sudah ada Perda yang melarang pengoperasian becak di Jakarta, saat ini becak masih beroperasi secara illegal di beberapa daerah di utara kota Jakarta seperti di Jelambar, Teluk Gong, Kapuk, Pluit, Tanjung Priok, Cilincing dan sekitarnya.
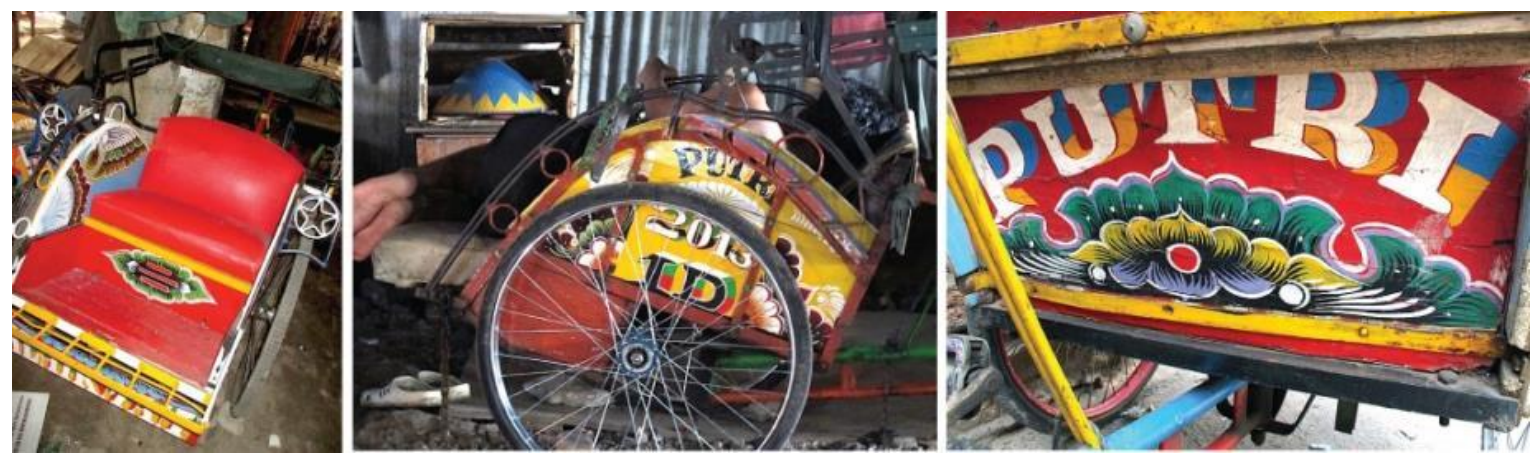

Gambar 2 Becak-becak Jakarta (Sumber: dok. aikon)

Pada badan becak-becak ini ditorehkan ilustrasi lukisan yang indah, dengan nama becak serta nomor lambung becak sesuai pesanan dari sang pemilik becak sebagai brand dari becaknya. Ilustrasi pada becak ini merupakan hasil karya pelukis becak, seperti Bapak Suminta yang tinggal di daerah Kapuk. Beliau memulai profesinya sebagai pelukis becak sejak tahun 1980 dan kerap dikunjungi oleh para pemilik becak yang ingin agar becaknya dilukis oleh Pak Suminta karena hasil karyanya yang indah. Obyek ilustrasi lukisan yang biasa beliau buat adalah lukisan pemandangan dan ornamen 
Indramayu. Ilustrasi ornamen Indramayu yang dilukis pada becak ini adalah pesanan yang paling banyak diminati oleh para pemilik becak. Mereka adalah kaum urban yang berasal dari Indramayu, Cirebon, Brebes dan Tegal. Oleh karena itu ornamen ini banyak disukai karena memiliki kedekatan dengan kampung halaman mereka. Selain itu ornamen dapat berfungsi sebagai penanda (visual identity) atas kepemilikan sehingga becak mudah dikenali oleh sesama pemilik atau pengemudi becak.

Hal ini senada dengan yang dikemukakan oleh Witabora (2012) yang mengatakan bahwa satu di antara peran ilustrasi adalah sebagai identitas. Peran ilustrasi juga digunakan dalam konteks pengenalan produk atau perusahaan, dapat memberi gambaran lebih dalam tentang perusahaan. Bentuk ilustrasi seperti ini sering dimanfaatkan sebagai elemen interior berupa lukisan-lukisan konsep. Ilustrasi memberikan dampak visual terkait dengan informasi dan promosi sebuah produk atau jasa.

Walaupun Indramayu berada di Jawa Barat yang notabene adalah tanah Pasundan yang berbudaya dan berbahasa Sunda, namun sebagian besar penduduk Indramayu berbahasa Jawa khas Indramayu. Masyarakat setempat menyebutnya dengan Basa Dermayon, yakni dialek Bahasa Jawa yang hampir serupa dengan dialek Cirebon. Di bagian selatan dan barat daya kabupaten ini, beberapa wilayah menggunakan bahasa Sunda, mengingat sejarah kabupaten Indramayu yang dulu pernah masuk ke dalam wilayah kerajaan Cirebon (di utara), sehingga bahasa Jawa memengaruhi masyarakatnya dalam berbahasa Sunda Khas Indramayu.

Ilustrasi ornamen bergaya dekoratif ini merupakan perwujudan dari figur flora (bunga) dan fauna (burung phoenix). Sunaryo (2009) menyebutkan bahwa motif hias burung phoenix banyak terdapat di daerah pesisir yang mendapat pengaruh Tiongkok, seperti di Cirebon, Pekalongan, Lasem dan juga Bali. Dalam motif hias, burung ini dianggap sebagai burung surga dan sebagai perlambangan dunia atas (langit). Sebagai ornamen, motif burung phoenix diterapkan pada batik, terutama batik pesisir, ukiran kayu dan lain-lain. Selain itu di kesultanan Cirebon, motif hias bunga teratai banyak diukirkan pada batu dan kayu. Teratai yang memiliki delapan helai mahkota bunganya melambangkan kemurnian dan kesucian.

Gaya ilustrasi dari ragam hias Indramayu ini terpengaruh dari batik Indramayu yang berciri khas pesisir dan memiliki corak yang berbeda dengan batik daerah pesisir lainnya, namun banyak mendapat pengaruh dari gaya Cirebon. Motif batik Indramayu disusun dengan sangat dinamis, memiliki ritme dan gaya perpaduan dengan motif yang diantaranya mendapat pengaruh dari Cina. Ciri yang menonjol pada batik Indramayu adalah langgam flora dan fauna yang diungkap secara datar, banyak bentuk lengkung dan garis yang meruncing (riritan), berlatar putih dan warna gelap, dan banyak titik yang dibuat dengan teknik cocohan jarum, serta bentuk isen-isen (sawut) yang berbentuk pendek dan terkesan kaku. 


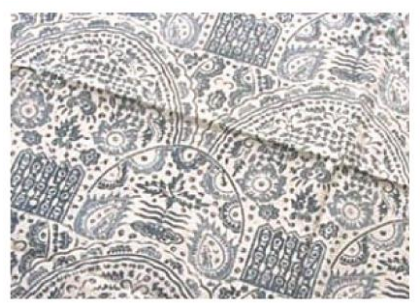

Kapal Kandas

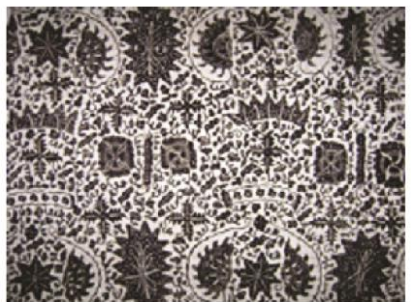

Jenderal Pesta

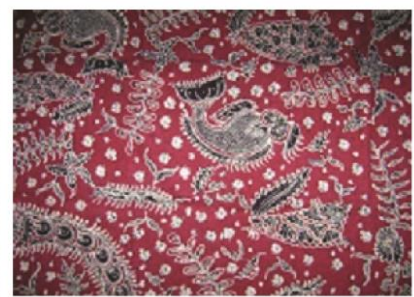

Iwak Entong

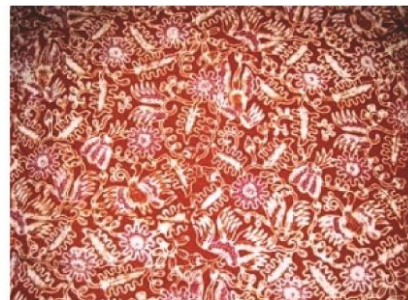

Kembang Gunda

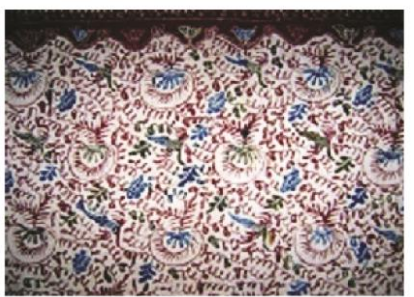

Jahe Serempang Kandang

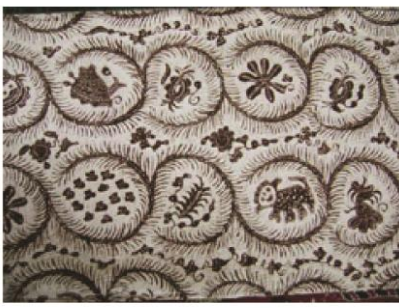

Ganggeng

Gambar 3 Aneka motif batik Indramayu

(Sumber http://fitinline.com/article/read/batik-indramayu)

Motif merupakan unsur pokok sebuah ornamen. Melalui motif, tema atau ide dasar sebuah ornamen dapat dikenali sebab perwujudan motif umumnya merupakan gubahan atas bentuk-bentuk di alam atau sebgai representasi alam yang kasat mata. Ragam hias Nusantara dari bentuknya terbagi menjadi dua jenis yaitu geometris (penyederhanaan bentuk-bentuk alam) dan organis (mencitrakan objek-objek yang ada di alam). Dari gaya ornamen, dapat dikelompokkan ornamen bergaya realis (bentuk sesuai dengan kenyataan), dekoratif (bersifat datar, tanpa menampakkan volume, tanpa perspektif), dan abstrak (bentuk yang sulit dikenali karena objek yang digambarkan digubah sedemikian jauh mengalami perubahan dan penyederhanaan) (Sunaryo, 2009).

Motif hias sulur yang merupakan stilisasi dari tumbuh-tumbuhan banyak diterapkan sebagai ornamen barang-barang dari perak, kuningan, ukir kayu dan lain-lain pada zaman sesudahnya memperlihatkan keanekaragaman dengan karakternya masing-masing. Beberapa motif hias ukir mendapatkan coraknya (langgam) berdasarkan asal tempat berkembangnya. Di antaranya ialah motif hias ukir Majapahit, Mataram, Pajajaran, Bali, Cirebon, Surakarta, Yogyakarta, Pekalongan, Jepara dan Madura (Sunaryo, 2009).

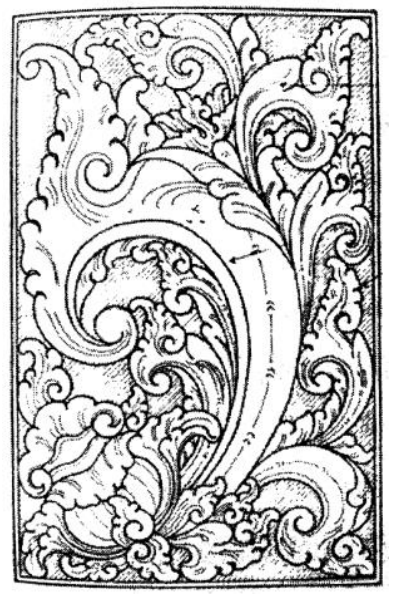

Gambar 4 Motif ukir floratif langgam Cirebon

(Sumber: Ornamen Nusantara) 
Ornamen Indramayu yang dilukis dengan indah pada badan becak Jakarta yang ada saat ini belum banyak digali, dikembangkan dan dimanfaatkan oleh masyarakat Indonesia, sementara keberadaannya terancam punah selaras dengan hilangnya becak di Jakarta. Di sisi lain peluang untuk penggunaan ornamen ini dapat dimanfaatkan secara lebih luas, terlebih dengan melihat fakta di lapangan bahwa batik Indramayu sendiri telah berhasil menembus pasar nasional dan internasional. Keindahan ornamen Indramayu pada becak ini menarik untuk dipelajari dan dikembangkan secara kontemporer. Oleh karena itu, sebelum karya lukis ornamen ini benar-benar punah dan dapat dimanfaatkan kembali secara maksimal maka perlu dilakukan pendokumentasian secara dijital sehingga ornamen Indramayu ini dapat diimplementasikan dengan mudah dan secara luas oleh masyarakat.

\section{METODE}

Penelitian dilakukan dengan metode penelitian kualitatif kebudayaan melalui tahapan: (1) Penentuan Lokasi Penelitian. (2) Penentuan Informan. (3) Pengumpulan Data (4) Analisis Data. Pengambilan data sebagai lokasi penelitian ditentukan di daerah Kapuk, yaitu lokasi di mana becak masih beroperasi di Jakarta dan bengkel tempat reparasi becak baik untuk perbaikan fisik dari armadanya maupun pelukisan becak. Di lokasi ini didapat seorang informan yaitu Bapak Suminta, seorang pelukis becak dari Cirebon yang sudah menjadi seniman lukis becak sejak tahun 1983. Sudah ribuan becak yang digambar olehnya, baik dengan gambar pemandangan maupun ornamen hias Indramayu yang merupakan mayoritas gambar yang tertoreh di becak-becak daerah Kapuk.

Selain wawancara dilakukan pula pengumpulan data visual di lapangan berupa gambargambar dalam bentuk foto dari beberapa becak yang masih beroperasi di daerah Kapuk dan mangkal di sekitar jembatan Bandengan Utara, Kampung Baru dengan menitikberatkan perhatian pada lukisan yang digambarkan pada badan-badan becak. Dari potret ini kemudian dilakukan analisis data yang prosesnya dilakukan terus-menerus baik di lapangan maupun setelah di lapangan. Analisis dilakukan dengan cara mengatur, mengurutkan, mengelompokkan dan mengkategorikan data. Pengkategorian berdasarkan bagian-bagian pada badan becak. Sebagai studi literatur data diperoleh lewat internet serta buku-buku mengenai ornamen dan batik.

\section{HASIL DAN PEMBAHASAN}

Dari hasil pemotretan di lapangan, yaitu di pangkalan becak daerah Kapuk dan Kampung Baru diperoleh data mengenai fisik dari becak dan beragam ilustrasi ragam hias Indramayu pada badan becak. Becak memiliki tiga roda seperti ban sepeda dan dibuat dari karet. Pelek sebagai landasan ban terbuat dari besi stainless. Stang digunakan sebagai alat pengendali atau pegangan agar kendaraan bisa dikendalikan jalannya. Jok untuk pengendara sama seperti jok pada sepeda. Adapun jok untuk penumpang ukurannya lebih besar sekitar $60 \mathrm{~cm}$, untuk diduduki oleh dua sampai tiga orang, terbuat dari bahan vinyl. Bagian atas becak diberi kap untuk menjaga agar penumpang tidak kehujanan atau kepanasan. Kap ini terbuat dari terpal tebal yang sisinya dikaitkan pada besi-besi tipis yang disambung dengan mur agar bisa dilipat. 


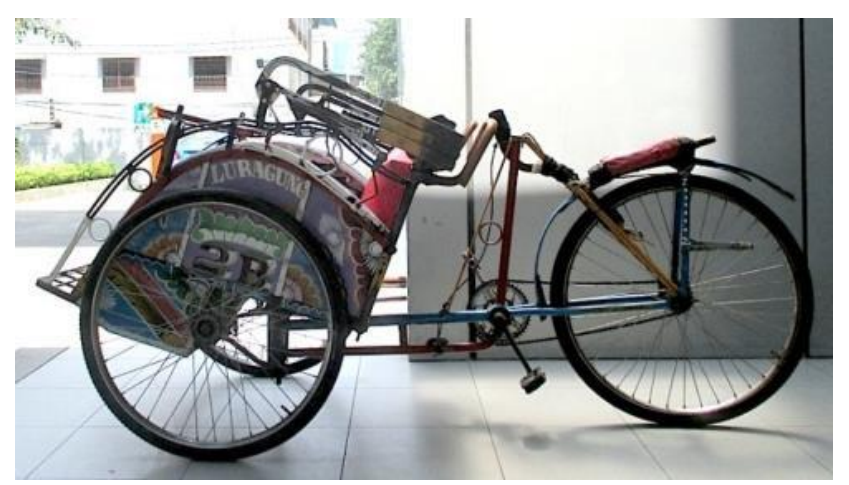

Gambar 5 Becak Jakarta kondisi kap dilipat

(Sumber: dok. pribadi)

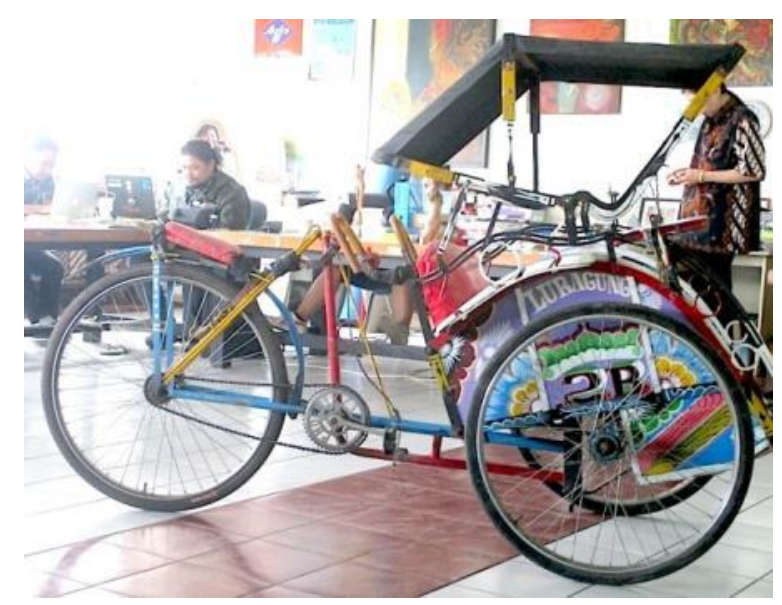

Gambar 6 Becak Jakarta kondisi kap dibuka

(Sumber: dok. pribadi)

Di lapangan diperoleh pula data berupa beragam ilustrasi ragam hias Indramayu pada badan becak. Dari pemotretan ini kemudian dilakukan proses analisis dengan mengurutkan, mengelompokkan dan mengkategorikan ornamen-ornamen yang terdapat pada badan becak. Untuk itu dilakukan pemotretan pada badan becak dengan memperhatikan bagian-bagian anatomi becak yang menjadi media lukis ornamen Indramayu, yaitu: (1) Samping bagian dalam. (2) Bagian belakang. (3) Samping luar bagian atas. (4) Samping luar bagian bawah.

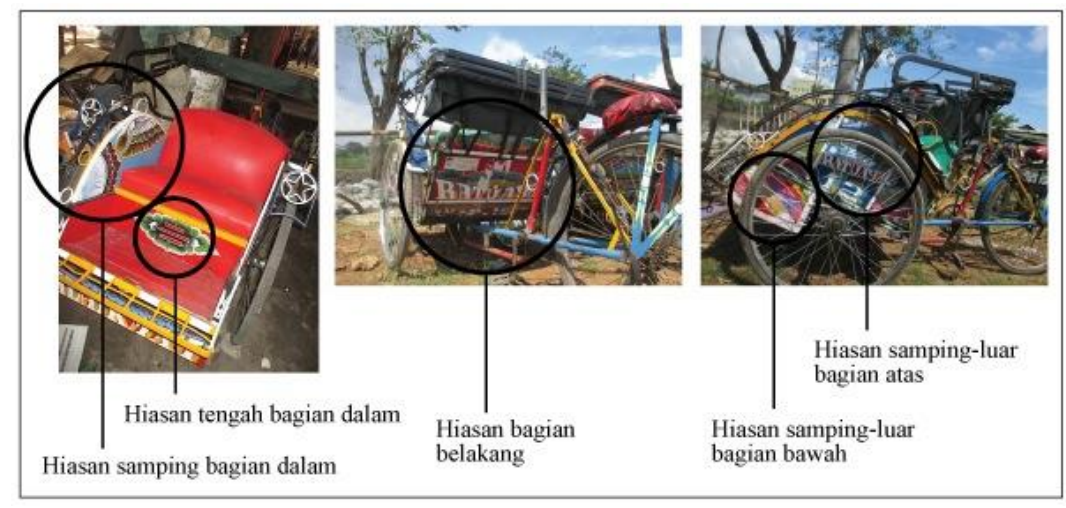

Gambar 7 Anatomi becak yang menjadi media lukis ornamen

(Sumber: dok. pribadi) 
Pada beberapa becak terlihat adanya kesamaan ragam hias pada hiasan samping bagian dalam. Selain bentuknya yang serupa, pewarnaannya pun dilakukan dengan cara yang sama, seperti yang terlihat pada gambar di bawah ini.

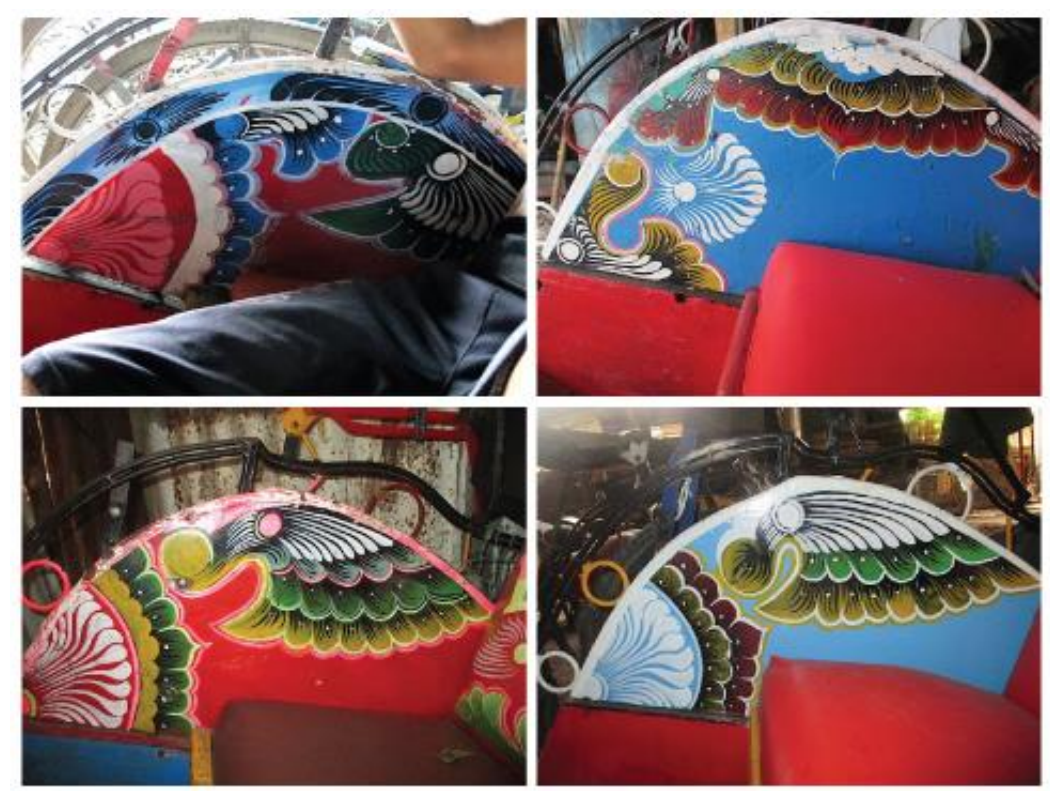

Gambar 8 Hiasan samping bagian dalam

(Sumber: dok. pribadi)

Sedangkan hiasan pada bagian belakang becak, tercantum nama becak, nomor lambung, tahun pembuatan lukisan dan tentunya ornamen Indramayu. Nama becak ditulis dengan huruf besar (all caps) dengan komposisi melengkung dan dilengkapi dengan bidang-bidang yang membentuk figur tiga dimensi. Pada beberapa becak tampak ornamen Indramayu dengan bentuk hiasan dan cara pewarnaan yang serupa antara satu becak dengan becak lainnya dengan beberapa pengembangan seperti yang tampak pada gambar di bawah ini.
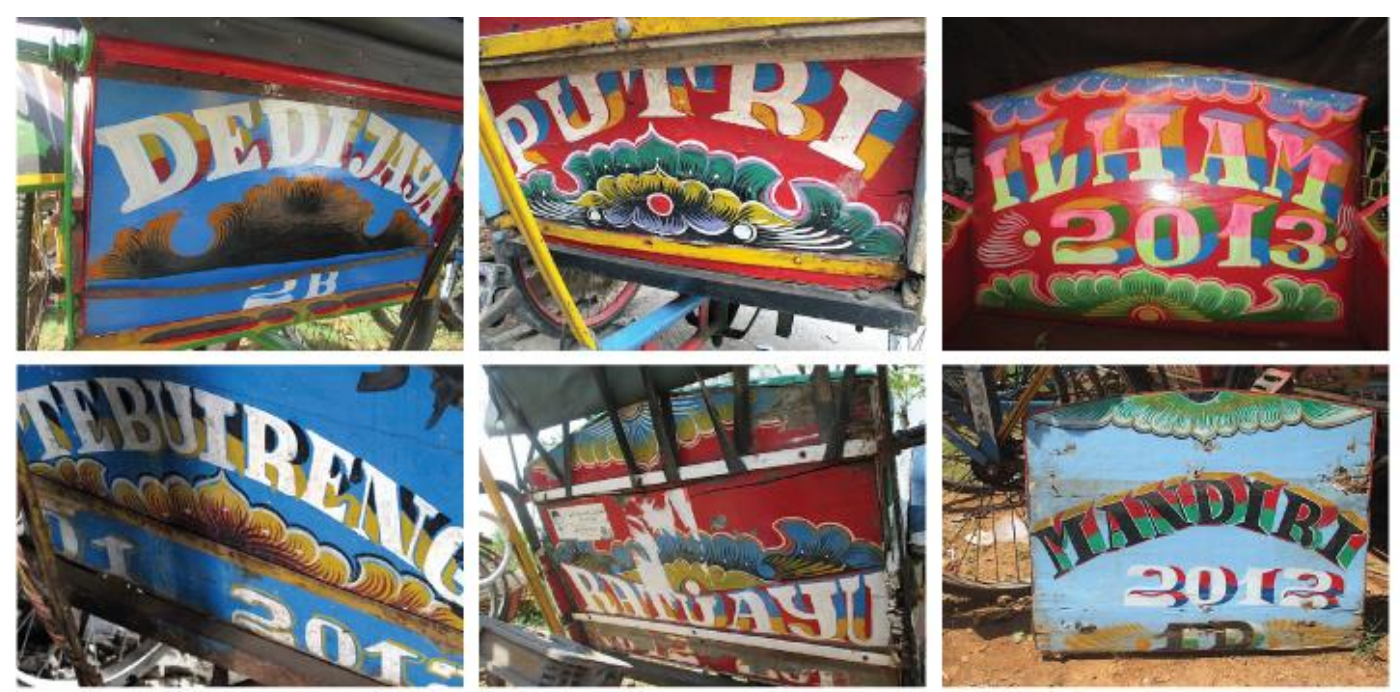

Gambar 9 Hiasan bagian belakang

(Sumber: dok. pribadi) 
Adapun hiasan di sisi samping luar bagian bawah, masih terlihat adanya kesamaan bentuk ornamen. Selain bentuknya yang serupa, pewarnaannya pun dilakukan dengan metode yang sama, seperti yang terlihat pada gambar berikut ini:
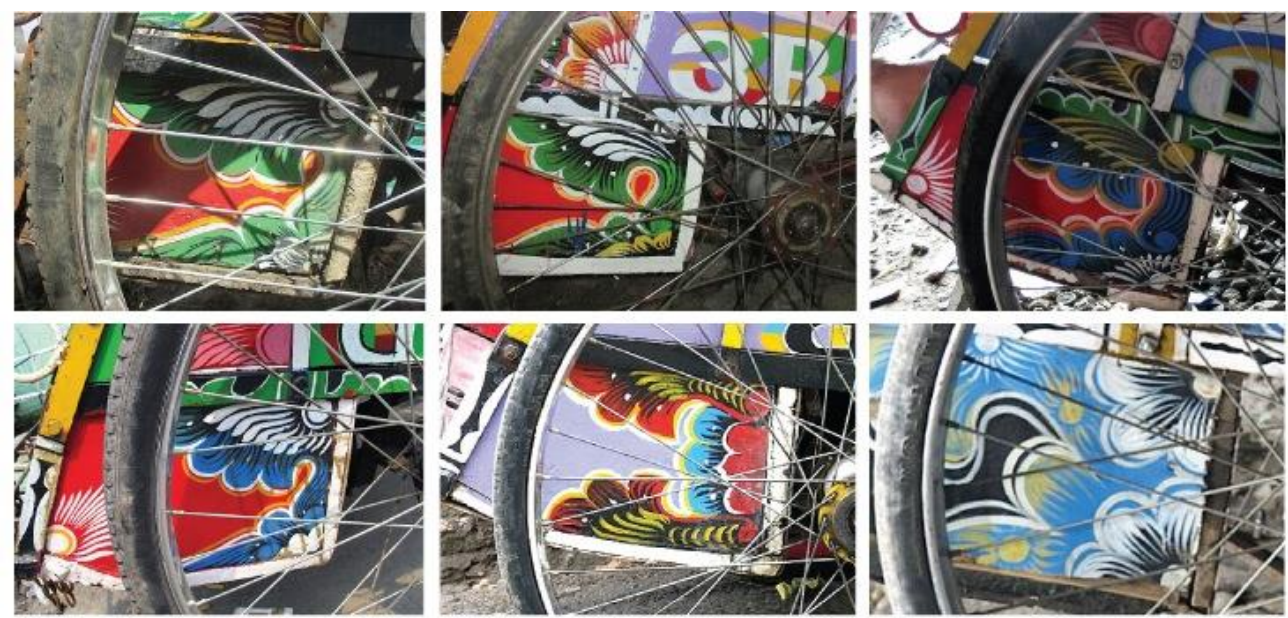

Gambar 10 Hiasan samping-luar bagian bawah (Sumber: dok. pribadi)

Seperti halnya hiasan pada bagian belakang becak, pada badan samping luar bagian atas tercantum nama becak, nomor lambung, dan tentunya ornamen Indramayu, namun tanpa tahun pembuatan lukisan. Nama becak ditulis dengan huruf besar (all caps) dengan komposisi melengkung dan dilengkapi dengan bidang-bidang yang membentuk figure tiga dimensi. Tampak ornamen Indramayu pada beberapa badan becak dengan bentuk hiasan yang serupa seperti halnya hiasan samping luar bagian bawah, dengan bentuk sebagai berikut.
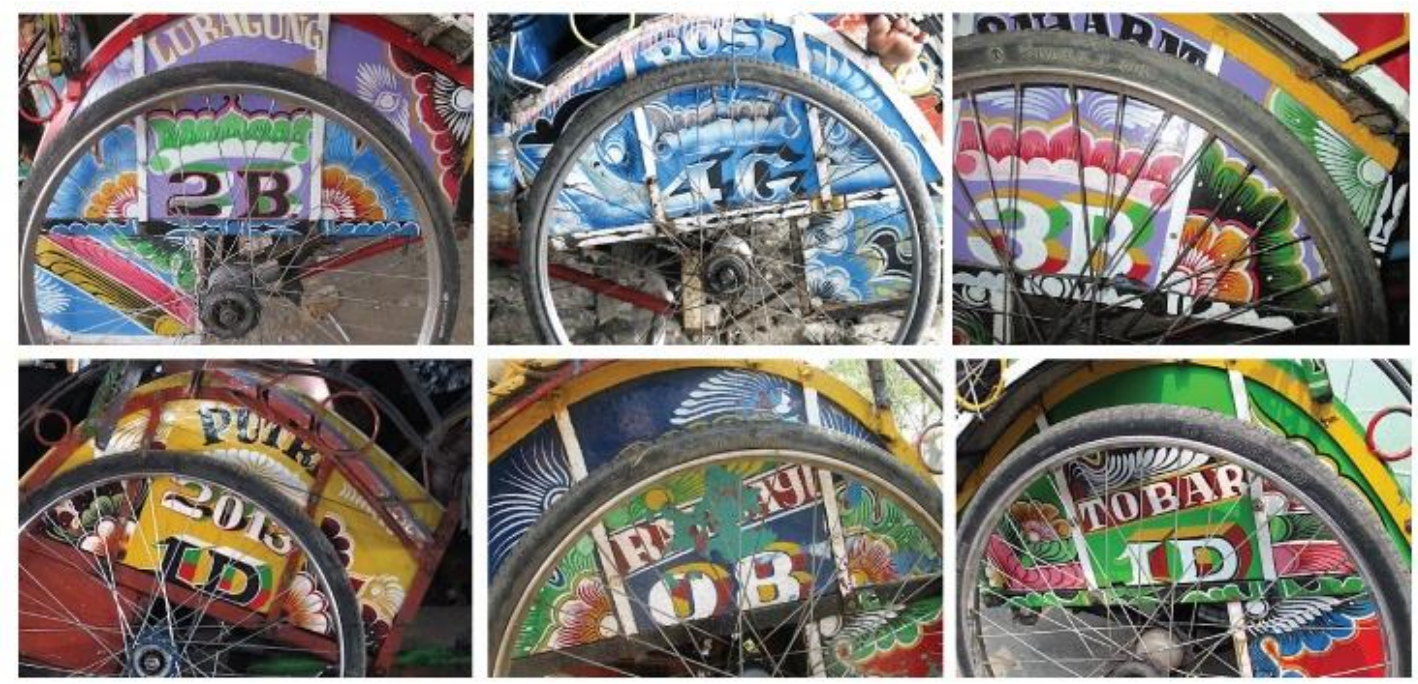

Gambar 11 Hiasan samping-luar bagian atas

(Sumber: dok. pribadi)

Dari beberapa contoh kasus ilustrasi ornamen pada badan becak di atas, kemudian dibuatkan sketsa dari ornamen Indramayu sebagai ragam hias pada becak Jakarta, seperti yang terlihat pada gambar di bawah ini: 

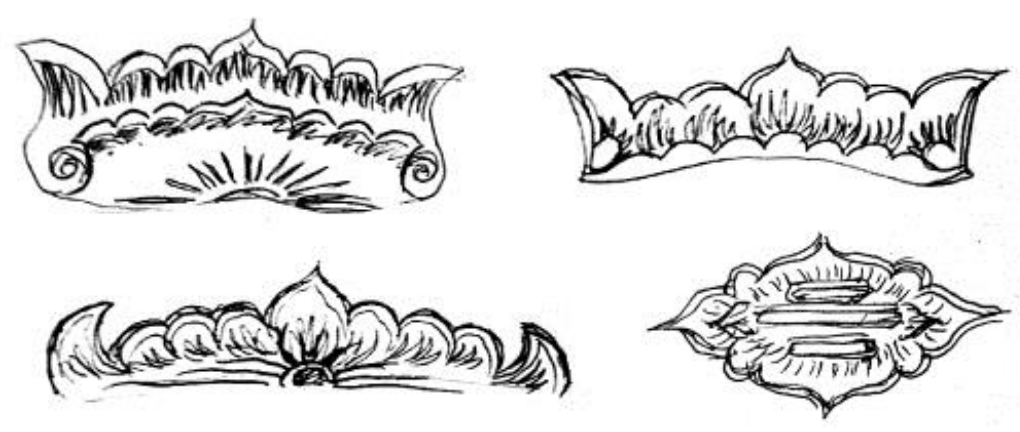

Hiasan untuk penempatan center

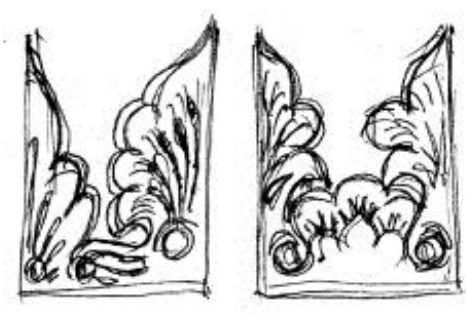

Hiasan untuk penempatan band (sebagai modul)

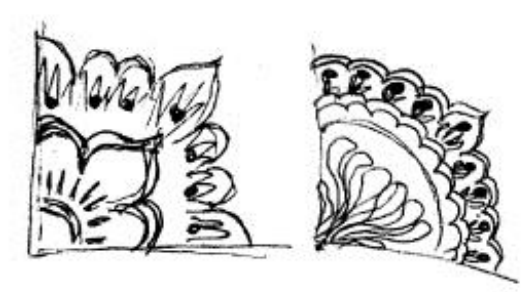

Hiasan untuk penempatan corner

Gambar 12 Sketsa motif-motif dari ornamen Indramayu

(Sumber: dok. pribadi)

Dengan memelajari sketsa ornamen di atas, dapat dilihat bahwa ornamen Indramayu pada badan becak Jakarta mudah dikenali dengan ciri khas yang tampak melalui bentuk dasar motif berupa lengkungan-lengkungan yang menyerupai daun, bunga teratai dan ekor burung, serta goresan-goresan seperti yang sering terlihat pada batik Indramayu. Goresan-goresan ini dikenal dengan istilah meruncing (riritan), serta bentuk isen-isen (sawut) yang berbentuk pendek dan terkesan kaku. Dalam pewarnaannya pun banyak menggunakan warna putih atau warna yang cenderung muda sebagai riritan dan warna hitam atau warna yang cenderung gelap sebagai sawut. Pada tepian bentuk lengkung diberi garis outline dua lapis di mana pada lapisan dalam menggunakan warna muda dan pada outline lapisan luar dengan warna yang lebih tua.

\section{SIMPULAN}

Ornamen Indramayu yang dilukis pada badan becak Jakarta memiliki kesan eksotis dan berdaya tarik tersendiri bagi para turis mancanegara. Ornamen yang bergaya dekoratif ini berpotensi untuk menjadi aset yang berharga untuk perkembangan dunia desain dan seni di Indonesia. Melalui pendokumentasian dan analisis atas ornamen ini, maka diperoleh bentuk-bentuk motif dari ornamen Indramayu yang dapat diterapkan pada ruang sesuai bidang penempatannya. Beberapa di antaranya sebagai hiasan center, corner bahkan band yang dapat tercipta dengan cara membuat pengulangan pada motif sebagai modul. Dengan memelajari ornamen ini secara mendalam maka dapat dilakukan pengembangan dari motif-motif ornamen untuk kebutuhan di masa kini yang tentunya akan memperkaya khazanah ragam hias Indonesia dan dimanfaatkan oleh para seniman visual, desainer dan arsitek untuk kebutuhan yang lebih luas. 


\section{DAFTAR PUSTAKA}

Eddi, P. (2013), Sejarah Becak. Museum Becak Indonesia, diakses 4 Mei 2014 dari http://museumbecakindonesia.blogspot.com/2013/06/sejarah-becak.html

Endraswara, S. (2006). Metode, Teori, Teknik Penelitian Kebudayaan. Yogyakarta: Pustaka Widyatama.

Fitiniline. 2 Maret (2013) Batik Indramayu. Fitinline, diakses 10 Desember 2013 dari http://fitinline.com/article/read/batik-indramayu

Halim, E. 6 Nopember (2013). Corak Indramayu di Penjaringan, Jakarta. Aikon.org, diakses 10 Desember 2013 dari http://aikon.org/corak-indramayu-di-penjaringan-jakarta/

Kubish, N. (2012). Ornaments: Pattern for Interior Design. Postdam: H. F. Ulmann Publishing.

Pemerintah Provinsi DKI Jakarta. (2010). Becak. Ensiklopedi Jakarta, diakses 4 Mei 2014 dari http://www.jakarta.go.id/web/encyclopedia/detail/132/Becak

Sunaryo, A. (2009). Ornamen Nusantara: Kajian Khusus tentang Ornamen Indonesia. Semarang: Dahara Prize.

Witabora, J. (2012). Peran dan Perkembangan Ilustrasi. Jurnal Humaniora, 3(2), 665-666. 